\title{
US company's gene therapy trial is first to bypass RAC for approval
}

Washington. Researchers at a US biotechnology company are expected to be the first group to conduct a gene-therapy experiment without receiving approval from the Recombinant DNA Advisory Committee (RAC), the government review committee set up more than 15 years ago to assuage public fears about experiments involving genetic manipulation. Last week, a committee of the US Food and Drug Administration (FDA) recommended that the agency allow Viagene Inc. of San Diego, California, to proceed with clinical trials of a gene therapy involving a human immunodeficiency virus (HIV) vaccine, the first time that such an experiment has been treated as a routine drug trial rather than a foray into unknown territory that requires extraordinary safety and ethics review.

Viagene was able to sidestep the usual RAC approval process because it is a private company and receives no federal funds. But with at least half a dozen similar companies preparing their own gene-therapy trials, this route is expected to become well-trodden as industry researchers seek to avoid the public hearings and scientific grilling of the RAC.

The FDA and the RAC differ in more than just name and methodology. In general, the RAC embodies much of the public concern of the late 1970 s and early 1980 s, and its 24-member panel includes lawyers, ethicists and political scientists as well as genetics researchers and clinicians. Its meetings are open, announced in advance and often attended by the media and those concerned about the use of genetic engineering techniques. The RAC has also taken a broad interpretation of its mandate to ensure that gene therapy protocols are safe and ethical.

To be ethical, in the RAC's view, an experiment must be conducted with all the appropriate patient consents and precautions and also have a reasonable chance of success. This generally requires researchers to demonstrate, with data from animal models and the like, that there is solid scientific evidence to suggest that the experiment will work in humans. For many groups, that has proved difficult. At a meeting earlier this month, the RAC rejected two protocols on the grounds that they had insufficient supporting data, and another protocol was withdrawn when it became clear that it, too, would be rejected for the same reasons.

The FDA, in contrast, is principally concerned about safety. For a Phase I trial - the very earliest of the three phases of approved clinical trials - the FDA generally wants to know only that the drug or therapy is not toxic and is not likely to harm patients. It relies on existing rules for obtaining proper consent, and, unlike the RAC, it treats gene therapy no differently from other drugs and therapies in that regard. Unless a company asks the FDA to open its approval process, it is generally closed from public view.

But as different as the two approval routes are, last week's launch of the FDA approval

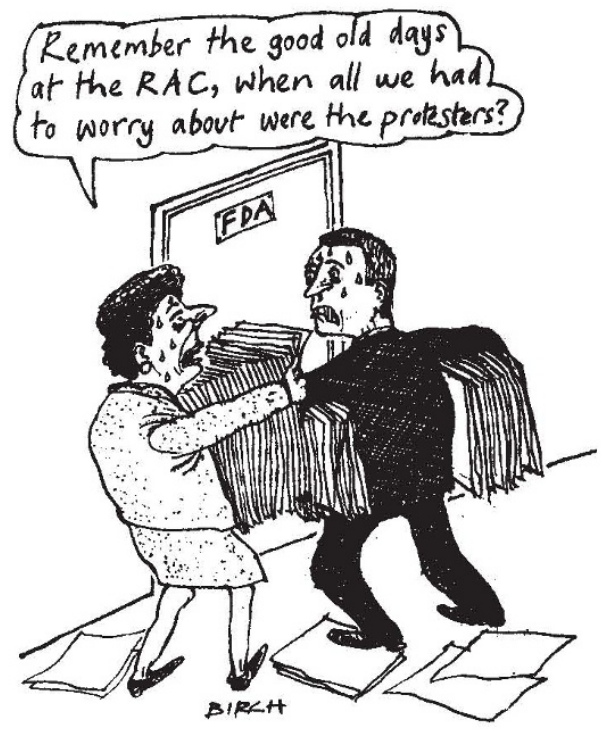

process resembled nothing more than the RAC itself. The review committee opened most of its deliberations to the public, and the FDA brought in six specialists to evaluate the scientific merits of the protocol. No one, however, expects the FDA to go to such extreme lengths for every protocol. In fact, most gene-therapy applications will probably be treated like any application for an experimental drug or therapy.

Viagene asked the FDA to conduct its review in public to remove suspicion that the company was trying to bypass the usual safeguards. "We felt that because it was the first one, we wanted it to be open", explains Steven Meto, vice president for research and development. But he predicts that "down the line, it may be more closed".

Meto says that he does not expect all industrial gene-therapy trials to go through the FDA. Some may have to be submitted to the RAC either because they are carried out with federal grants or because the institutions that do the clinical trials receive federal funds.

Another disincentive for companies is the length of the FDA process. Viagene, for example, spent a year and half developing some 3,000 pages of documentation just to get to Phase I clinical trial approval. Of course, all gene-therapy protocols must receive some sort of FDA approval, whether they go through the RAC or not, and if a company intends to market a product it will eventually have to receive full FDA marketing approval. But the RAC, despite its public nature and its hunger for efficacy data, may be easier for those conducting basic research and for protocols that do not have a near-term therapeutic goal.

Some of those who called for the creation of the RAC are hoping that companies will continue to use the committee voluntarily. "We're concerned that as gene therapy gets more sophisticated, the process is getting less accountable," says Andrew Kimbrell, an attorney at the Foundation for Economic Trends, the umbrella organization for biotechnology gadfly Jeremy Rifkin. He notes that the FDA cannot match the in-house scientific expertise of the RAC. "I'm sure that the FDA is not the proper body to regulate what is involved", he says. "I'm very concerned about private companies using this route." FDA officials say that they will continue to use outside experts as necessary.

But in the face of increasing acceptance of gene therapy, those who still wish for special reviews of everything from the basic biology to the theology of simple gene-transfer experiments appear to be losing ground to those who argue for business as usual.

Christopher Anderson

\section{OED on CD}

London. What do the words 'heterogenist', 'condensational', 'subfraction' and 'zooarchaeologist' have in common? According to the Oxford English Dictionary (2nd edition), they all had their first recorded use - in 1870, 1903, 1946 and 1987 respectively - in Nature. This week's launching of the compact disc version of the dictionary will give philologists a chance to explore in ways not previously possible the half a million definitions and 2.4 million quotations contained in the printed edition.

Searches can now be made for headwords, phrases and variant forms, and the text can be perused according to date, quotation, pronunciation, definition, etymology and much more. For example, Nature has been cited 9,737 times for early use of such words as 'filter', 'urogastrone', 'abactinal' and 'stagnating'. In comparison, Science has around 1,000 citations, New Scientist more than 2,300 and The Times an impressive 19,603. The new electronic version of the dictionary is published by Oxford University Press on a single compact disc priced at just under $£ 600$.

Poter Tallack 